\title{
Representações sociais de licenciandos sobre ser professor de ciências
}

\section{Social representations of licentiate about being science teacher}

\author{
${ }^{1}$ Heloisa Fernanda Ortêncio Negri helonegri@gmail.com \\ ${ }^{2}$ Carlos Alberto Oliveira Magalhães Júnior \\ ${ }^{3}$ Celia Tamara Coêlho \\ ${ }^{4}$ Cristiano Domingues da Silva \\ ${ }^{5}$ Felipe da Silva Triani
}

\section{RESUMO:}

O objetivo foi investigar as Representações Sociais (RS) que licenciandos em Ciências da Universidade Estadual de Maringá têm sobre a atividade docente nesta área. Identificamos as representações sociais e o núcleo central por meio da entrevista semiestruturada e da técnica de evocação livre de palavras como instrumentos de coleta de dados, já a técnica de análise de conteúdo foi adotada como instrumentos de análise de dados. Os resultados apresentados por meio de entrevistas semiestruturadas são de que os acadêmicos possuem uma representação social na formação de professores de Ciências pautada na formação conteudista. Sobre "Ser professor de Ciências", como resultado do núcleo central nos $3^{\circ}$ anos encontramos a palavra "Inteligente", e nos $4^{\circ}$ anos o núcleo central foi apontado pelas palavras "Conhecimento" e "Sentimento". Foi possível acentuar por meio da análise dos planos de aulas e relatórios que os acadêmicos possuem uma representação social baseada no livro didático, e a prática de ensino pautada na teoria tradicional de ensino.

Palavras-chave: Formação. Representação social. Licenciandos ciências.

\begin{abstract}
:
The aim of this study was to investigate the social representations (RS) that graduates of Degree Course in Sciences of the State University of Maringa, have on the teaching activity in this area. Identify the social representations and the core that the licensees through semi-structured interview, free evocation of words technique, essays content analysis and analysis of lesson plans and reports. The results presented through semi-structured interviews are that academics have a social representation in the training of science teachers guided the conteudista training. On the theme "Being a science teacher" as a result of the central core in the 3rd years we find the word intelligent in the 4th year the core indicated on the same topic was nominated the words Knowledge and feeling. Could stress through the analysis of lesson plans and curriculum that academics have a social representation based on the textbook, and guided teaching practice the traditional teaching theory.
\end{abstract}

Keywords: Education. Social representation. Undergraduate sciences.

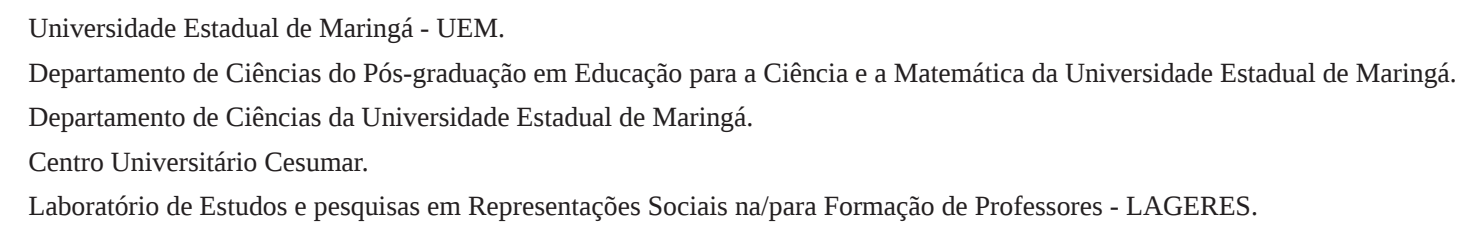




\section{CONSIDERAÇÕES INICIAIS}

O presente manuscrito é resultado de investigações acerca das Representações Sociais (RS) de licenciandos sobre "Ser Professor de Ciências", buscando conhecer a formação de professores e os seus questionamentos sobre a prática docente. Nesse viés e em meio aos problemas da prática educacional para atuação nos estágios e as dificuldades de alcançar um método satisfatório e didático, foram necessários estudos acerca da formação de professores de ciências no Ensino Superior. Então, buscamos autores que nos apresentassem este tema com autonomia.

Essas dificuldades se refletem no ensino dos graduandos na área de ciências, considerando que os professores destes universitários acabam por ensinar matérias apenas para as práticas de estágio, deixando de oferecer conteúdos que mudarão a postura e a forma de agir desses alunos em formação (GATTI, 2003).

Diante do problema de pesquisa abordado na formação docente do curso de Licenciatura Plena em Ciências, o autor Dermeval Saviani (2009) apresenta modelos de formação para que os futuros professores possam ampliar as suas ideias e atuar em sala de aula com novos métodos.

Os modelos propostos por Saviani são: conteúdos culturais-cognitivos, que consagram um domínio específico relativo à área em que o professore irá lecionar; e o pedagógico-didático, o qual, diferentemente do modelo anterior, sustenta que a formação do professor somente se completará com o bom preparo pedagógico e didático.

Para tanto, sabemos que os acadêmicos de ciências estão inseridos em grupos com representações sociais, o que nos leva a compreender que os conhecimentos ensinados pelos professores são filtrados. Como consequência disso, há ocasiões em que os conteúdos acabam não sendo adquiridos com o sentido que deveriam, não sendo apenas problemas teóricos ou cognitivos do aluno ou professor, mas socioafetivo e cultural, isto é, as representações sociais. Estas representações sociais se mostram as razões pelas quais a formação de professores se torna ineficaz por muitas vezes ou, não alcança o objetivo das suas práticas e posturas.

\footnotetext{
É preciso ver os professores não como seres abstratos, ou essencialmente intelectuais, mas, como seres essencialmente sociais, com suas identidades pessoais e profissionais, imersos numa vida grupal na qual partilham uma cultura, derivando seus conhecimentos, valores e atitudes dessas relações, com base nas representações constituídas nesse processo que é, ao mesmo tempo, social e intersubjetivo. Há também que se considerar o papel de eventos mais amplos, sejam sociais, políticos, econômicos ou culturais, com seus determinantes que perpassam a vida grupal ou comunitária. Sabemos que a interação desses fatores molda as concepções sobre educação, ensino, papel profissional, e as práticas a elas ligadas, concepções e práticas estas que, por sua vez, são estruturalmente delimitadas pela maneira que as pessoas se veem, como estruturam suas representações, como se descrevem, como veem os outros e a sociedade à qual pertencem (GATTI, 2003, p. 196).
}

Sabemos que a formação de professores é um processo difícil e ainda adequar-se às mudanças sobre a representação social do professor, enraizada por pensamentos e ações contidas em nossas representações sociais, é uma tarefa difícil, no entanto necessária. Dessa maneira, Franco (2008) discute que a atividade docente está relacionada com as nossas condições sociais, psicológicas e emocionais, deste modo se torna um processo pelo qual as características pessoais e culturais dos educadores intervêm e alteram sua prática. $\mathrm{O}$ autor destaca: "fica claro que a escola não se transforma por projetos inovadores, normalmente imposto às escolas por via burocrática. A escola só mudará quando os educadores, em coletivo, perceberem que a escola pode e deve ser outra” (FRANCO, 2008, p. 115). Além disso, a autora acrescenta:

A grande dificuldade em relação à formação de professores é que se quisermos ter bons professores, teremos que os formar como sujeitos capazes de produzir ações e saberes, consciente de seu compromisso social e político. Não dá para formar professores como objetos dotados de habilidades e competências, instaladas de fora para dentro, sob forma de fazeres descobertos por outros, que nada significam na hora da prática (FRANCO, 2008, p. 220). 
Acreditamos na importância de apresentar os aspectos culturais e psicossociais na formação de professores de ciências, para a aprendizagem de novos valores e nas conseguintes mudanças nas práticas de atuação no estágio.

O conhecimento é enraizado na vida social, expressando e estruturando a identidade e as condições sociais dos que dele partilham. Por isso, ações sociais ou educacionais que têm por objetivo criar condições de mudanças conceituais, de atitudes e práticas precisam estar engrenadas com o meio sociocultural no qual as pessoas, os profissionais, que serão abrangidos por essas ações, vivem (GATTI, 2003, p. 197).

Gatti (2003) acredita que os conceitos e práticas do cotidiano acadêmico são permeados por inter-relações entre ideias e representações que constituem uma sociedade em que os indivíduos criam para si mesmos em consequência de suas relações em grupos.

\section{1 Alguns Apontamentos Acerca da Representação Social}

A Teoria das Representações Sociais foi proposta por Serge Moscovici com a publicação de sua tese de doutorado em 1961 (TRIANI et al., 2015), sendo considerado um marco da integração entre os fenômenos perceptivos individuais e sociais e tem sido utilizada em diversos outros ramos do saber (MOSCOVICI, 1972). A partir de sua publicação, a teoria foi inicialmente empregada em estudos psicossociais, bem como utilizada em diversos outros ramos do saber.

Estudos (NAIFF et al., 2009) apontam que pensar a respeito das representações sociais, seria considerá-las enquanto emergentes na dimensão simbólica da vida social, pois servem para agir sobre o mundo e sobre os outros. As representações sociais nascem no cotidiano, nas relações que estabelecemos, sendo em família, escola, trabalho, entre outros contextos da vida social, ou seja, onde existir uma realidade a ser apropriada e partilhada (JODELET, 2001).

Para uma das autoras de referência em estudos psicossociais, Jodelet (2001), a representação social é uma construção representativa criada para indicar e resolver problemas do senso comum e uma forma de nomear e definir os aspectos da realidade e conhecimento elaborado a um objeto e compartilhado a um conjunto social comum. Segundo a autora, as representações sociais podem ser consideradas "uma forma de conhecimento, socialmente elaborada e partilhada, com um objetivo prático, e que contribui para a construção de uma realidade comum a um conjunto social” (JODELET, 2001 p. 22).

As representações sociais são compostas de um conjunto organizado de ideias e informações, crenças, opiniões e atitudes. Para Moscovici (1978) as RS se concretizam por meio de uma fala, um gesto e um encontro em nosso cotidiano. O indivíduo, ao nascer, já está inserido em um meio social que possui imagens e linguagens, então, este já se encontra em um mundo de representações em suas respectivas dimensões que permeiam entre as mentes e possuem uma dimensão histórica e transformadora do sujeito.

Segundo Jodelet (2001, p.22), “as representações sociais são abordadas, concomitantemente, como produto e processos de uma atividade de apropriação da realidade do exterior ao pensamento e de elaboração psicológica e social dessa realidade”.

As RS nascem nas relações que criamos com grupos em comuns, como, família e escola, tendo parte o senso comum e o científico (MAGALHÃES JÚNIOR; TOMANIK, 2012, p. 230). Essas representações sociais também pertencem a significados não apenas vinculados à relação pensamento e linguagem, mas por um conjunto de concepções que os sujeitos podem ter sobre realidades do universo cultural. 
Entende-se que o homem é um ser social, participante de diversas ideias sobre os mais variados assuntos que sejam do seu interesse e curiosidade. Nessa relação de opiniões, cada indivíduo defende seu próprio conceito, formado por uma coleta de informações com valores de diversas experiências pessoais e grupais.

Portanto, Moscovici (1978) enfatiza que as RS não são apenas “opiniões sobre”, são teorias coletivas sobre o real, baseados em valores que determinarão as ideias compartilhadas pelos grupos.

\subsubsection{Abordagem Estrutural das Representações Sociais: o Núcleo Central}

O Núcleo Central, uma das partes o qual compõe a Representação Social, apresenta a maior dificuldade de mudança, resistente, proposto por Jean Claude Abric no ano de 1976, chamada de "abordagem estrutural das representações sociais” (CAMPOS; ROUQUETTE, 2003). A teoria trata das Representações Sociais, que é organizada em meio a um Núcleo Central (NC), que determina o significado e a organização da representação social, bem como consistência e permanência a esta representação, sendo estável e resistindo às mudanças, além de outros elementos não principais chamados de Elementos Periféricos (EP) que também compõem a RS.

Alves-Mazzotti (2001), apresenta o núcleo central como sendo determinado pela natureza do objeto representado e pela relação que o grupo mantém com o objeto, enfim, pelo sistema de valores que formam o grupo social. A autora acredita que o NC é determinado e influenciado pelas condições históricas, sociológicas e ideológicas do indivíduo e o grupo o qual ele pertence, sendo assim, uma base comum compartilhada entre o grupo específico, base a qual, que por meio dela, podemos identificar o núcleo central dos mesmos.

Desse modo, o núcleo central é apresentado como uma base propriamente social e coletiva, o qual define a homogeneidade de um grupo. Por sua vez, o sistema periférico é o elemento que se permite uma adaptação, uma diferenciação em função do vivido, uma integração das experiências cotidianas, permitem ainda modulações pessoais em referência ao núcleo central comum, gerando representações sociais individualizadas (ALVES-MAZZOTTI, 2001).

Sá (1996), ao se referir aos componentes do núcleo central e os elementos periféricos das RS, relata que estes funcionam exatamente como uma entidade, onde cada parte tem uma função específica e complementar da outra parte. Para o autor, o núcleo central, pose ser considerado um subconjunto da representação, cuja ausência de algum elemento, destruiria a representação do objeto ou a mudaria.

O núcleo central desempenha funções importantes na representação de um determinado objeto, a primeira, "Função Geradora”, a qual se cria ou se transforma o significado dos elementos da representação, por meio dela que outros elementos ganham sentido, e, ainda, a "Função Organizadora”, que organiza as ligações entre os elementos de uma representação, ou seja, o núcleo é o elemento unificador e estabilizador da representação (SÁ, 1996). Ainda segundo este autor, o NC teria uma prioridade, trataria do elemento mais estável da representação social, por ele estar dentro da representação social, o NC é o elemento que resistirá a mudanças. Isso porque, se ocorrer uma modificação do núcleo central, provocaria uma transformação completa da representação. “O núcleo central é constituído de um ou alguns elementos que ocupam na estrutura da representação uma posição privilegiada” (SÁ, 1996, p. 71).

Sá (1996) apresentou um sistema baseado nos estudos de Abric, neste sentido do Núcleo Central ligado à memória coletiva e história do grupo, estável e rígido e, que por sua vez, resiste à mudança e determina a organização e o significado da representação. No entanto, em torno do Núcleo Central organizam-se os Elementos Periféricos que permitem integração das experiências e histórias individuais, sendo flexível e capaz de se transformar, permitindo a realidade concreta dos fatos. Eles ainda constituem o conteúdo essencial da representação. Sá (1996) nomeia três funções que o sistema periférico possui, nelas pertencem características importantes que ajudam a determinar o núcleo central. 
A primeira seria a função de Concretização, a qual depende do contexto para resultarem a representação da realidade. A segunda seria a função de Regulação, a qual, as informações novas ou as transformações do meio social podem ser integradas no periférico das representações. Por fim, a função de Defesa, a qual o núcleo central de uma representação resiste a mudança, então, o sistema periférico é como o sistema de defesa da representação.

Com base nos autores elencados entendemos que o núcleo central é a base da representação social coletiva/grupo que define a sua homogeneidade, por sua vez, o sistema periférico é o mecanismo da representação que permite uma adaptação, diferenciação em função do objeto, uma integração das experiências cotidianas.

Neste contexto, o objetivo deste trabalho foi investigar as representações sociais que os acadêmicos do Estágio Supervisionado I e II têm em meio aos problemas da prática educacional para atuação nos estágios e as dificuldades de alcançar um método satisfatório e didático pedagógico.

\section{METODOLOGIA}

Desenvolvemos a pesquisa na Universidade Estadual de Maringá, Campus Regional de Goioerê, no Curso de Licenciatura Plena em Ciências. No primeiro momento, utilizamos entrevistas semiestruturadas como instrumento para coleta de dados, a qual Alves-Mazzotti e Gewandsnajder (1998) discutem que se têm a vantagem de permitir ao entrevistador uma pré-sistematização das questões e por outro lado deixamos o entrevistado à vontade para falar. Os nomes dos acadêmicos foram mantidos em sigilo, 6 alunos foram entrevistados e para identificá-los apresentaremos A1 para o primeiro aluno, seguindo respectivamente até o aluno A6.

O roteiro de entrevista abrangeu informações como: concepção da atividade docente; planejamento de aulas; grau de motivação e tipos de práticas educativas mais presentes nos planejamentos feitos por eles e expectativas em relação a ser professor de Ciências. Assim, buscamos conhecer e analisar as representações sociais dos licenciandos a partir do contexto social e conteúdos históricos que instruem esses graduandos enquanto sujeitos sociais, procurando identificar as interpretações dadas aos temas relacionados à prática de ensino em ciências e as suas expectativas em relação à profissão de professor (SPINK, 2002).

A entrevista semiestruturada aconteceu individualmente para que os estudantes pudessem responder às perguntas sem timidez e com precisão, em uma das salas de professores do campus de Goioerê. As perguntas foram gravadas com um celular e algumas informações relevantes também foram anotadas.

No segundo momento, trabalhamos com Evocação Livre de Palavras (ELP) (CARMO; LEITE; MAGALHÃES JÚNIOR, 2017) e redação sobre "Ser Professor de Ciências", para que diante disto pudéssemos identificar o núcleo central das representações sociais que permeia a trajetória destes docentes em formação. Tivemos como envolvidos alunos que cursaram a disciplina de Estágio Supervisionado em Ciências I, do $3^{\circ}$ ano, num total de sete alunos, sendo cinco acadêmicos do ano de 2012 (100\%) e dois no ano de 2013 (66,6\%). Da disciplina de Estágio Supervisionado em Ciências II, do $4^{\circ}$ ano, um total de 17 alunos, sendo 12 acadêmicos no ano de 2012 (100\%) e 5 no ano de 2013 (100\%). Portando, a amostra foi composta por 24 estudantes.

Esse segundo momento foi baseado em duas dimensões. A primeira consistiu na ELP (SÁ, 2000; CARMO; LEITE; MAGALHÃES JÚNIOR, 2017), na qual os acadêmicos escreveram as cinco primeiras palavras que lhe viessem à mente em relação a "Ser professor de Ciências" e, em seguida, classificaram-nas segundo o grau de importância, atribuindo o número um (1) para a mais importante e assim, respectivamente, até o cinco (5), considerado o menos importante (NAIFF et al., 2009; ROCHA, 2009). Segundo os mesmos autores, essa técnica de hierarquização das palavras permite a reavaliação da ordem em que foram prontamente evocadas, possibilitando uma organização cognitiva desses termos. 
Nessa mesma perspectiva, a segunda dimensão constituiu-se na solicitação de uma dissertação, em até 20 linhas, sobre o mesmo tema: "Ser professor de Ciências".

As análises das evocações de palavras foram realizadas segundo a identificação do núcleo central e elementos periféricos das representações sociais, como sugerido por Sá (1996, 2000) e Naiff e seus colaboradores (2009). Por meio da proposta feita por Cortes Junior e outros (2009), para determinação da Ordem Média de Evocação em conjunto com a frequência média das evocações (ROCHA, 2009), foi possível identificar o núcleo central e os elementos periféricos. Para isso, utilizamos a fórmula ${ }^{6}$ proposta por Cortes Junior e outros pesquisadores (2009) e Magalhães Júnior e Tomanik (2012).

As palavras evocadas foram organizadas em um quadro com quatro quadrantes. Segundo os autores citados, no primeiro quadrante estão os elementos pertencentes ao núcleo central, sendo os elementos que apresentaram maior frequência e menor ordem média de evocação. No quarto quadrante, encontram-se os elementos periféricos, pouco evocados e com alta ordem média de evocação. No segundo e terceiro quadrantes encontram-se os elementos intermediários (MARQUES et al., 2004).

Para garantir melhor compreensão da influência das RS, nas atividades de docência dos acadêmicos, foram analisados os planejamentos das aulas para o estágio curricular supervisionado II do ano de 2013 e os relatórios sobre o estágio docência, que se encontraram disponíveis no portfólio de estágio.

\section{A EMERGÊNCIA DAS REPRESENTAÇÕES SOCIAIS DO SER PROFESSOR DE CIÊNCIAS EM DISCUSSÃO}

Nas entrevistas semiestruturadas a média de idade dos estudantes eram de vinte e dois anos. Quatro estudantes moravam em Goioerê, no Jardim Universitário e Centro e, outros dois residiam em estradas próximas a cidade, zona rural.

Da primeira questão, quando indagados sobre os motivos que os levaram a escolher o curso de Licenciatura Plena em Ciências, a resposta de quatro, dos seis alunos entrevistados foram por ser próximo às suas casas, gratuito e por falta de opção de outros cursos, e dois responderam que gostavam da matéria, biologia, então acabaram se interessando pelo currículo do curso de licenciatura.

A segunda questão, sobre as atividades que os graduandos imaginavam ser desempenhadas pelo profissional formado na área, todos responderam que poderiam ser professores e dois acrescentaram, ainda, que gostam de trabalhar com laboratórios e experiências. Na sequência, indagamos os estudantes sobre como imaginam que irão exercer a profissão após concluir o curso de Licenciatura Plena em Ciências. Quatro estudantes responderam que gostariam de lecionar, no ensino fundamental e dois também afirmaram que após concluir o curso pensam em fazer mestrado na área. Sobre este aspecto, o entrevistado 5 afirmou que: "Eu gostaria muito de fazer pesquisa depois que eu me formasse, tanto é que eu vou tentar o mestrado esse ano, acho a área de pesquisa muito importante, interessante, queria muito exercer a profissão como professor também, me atrai bastante” (A5).

Outra questão presente na entrevista era a descrição de alguma lembrança ou imagem que possuem dos profissionais do ensino de ciências, os quais já tiveram contato no decorrer da vida escolar. A maioria dos aca-

6 Ordem Média de Evocação $=\frac{\sum_{1}^{n} \text { P.G }}{\mathrm{f}}$

Somatória $(\Sigma)$ do número de vezes que a palavra foi evocada (P), numa dada posição de grau de importância, vezes seu grau de importância (G), dividido pela frequência que a palavra foi evocada no total. 
dêmicos responderam que não possuem nenhuma lembrança específica dos profissionais. Apenas dois responderam que tiverem professores que marcaram a vida escolar. Vejamos a fala de um dos estudantes:

"Olha, tem uma professora que me marcou bastante, devido às atividades que ela dava, ela levava a gente pra aula de campo, dava atividade que nem de cuidar de ovo de galinha como se fosse um filho, ela dava umas coisas diferentes, ela marcou por isso, fazer essa contextualização” (A4).

Outro entrevistado afirmou que:

\begin{abstract}
"Bom, eu tinha um professor que ele gostava muito de fazer desafio, então sempre, no começo da aula, ele trazia um desafio e isso me lembra bastante dele. Ele fazia esse desafio pra gente, mas não falava nada pra gente como era e, na próxima aula, ele dava resposta. Então, isso fazia com que a gente buscasse do que se tratava (A5)”
\end{abstract}

Quando questionados sobre como se imaginam atuando daqui alguns anos, os entrevistados responderam que pretendem ser bons professores. Nesse sentido, disseram que querem ser criativos e não apenas ensinar conteúdos para que os alunos possam ser aprovados no vestibular, mas sim, ensinar conteúdos que possam contribuir para a vida do aluno. Sobre este aspecto um dos informantes relatou detalhadamente como se imagina atuando daqui a alguns anos:

\begin{abstract}
"Eu quero tentar exercer a grande maioria das coisas que eu aprendi, ser mais criativa, tentar ter uma relação boa de professor aluno, também fazer com que eu desperte a vontade do aluno em aprender fazendo investigações nos conhecimentos que eles tem, porque eu aprendi que é muito importante fazer isso, levantar questionamentos, conhecimentos que eles já possuem, pra você desenvolver sua aula, porque até facilita mais, faz com que eles se sintam mais à vontade, participarem da aula, trazer pra sala de aula modelos mais didáticos, diferentes, um dia trazer um experimento, uma aula de campo, um jogo, cada dia ficar diferente, utilizar um livro, porque na escola na maioria das vezes é obrigado, aqui na cidade é obrigado, o professor pode utilizar outra coisa mas o livro didático não é largado, eu quero tentar fazer isso" (A6).
\end{abstract}

No que diz respeito ao questionamento sobre o que é ser um bom professor de Ciências, todos os entrevistados apontaram que ser um bom professor é desenvolver habilidades, como, ser paciente, saber explorar os conteúdos, ter o domínio da sala de aula, trabalhar questões do cotidiano, levar em conta a realidade dos educandos, para que os alunos entendam a ciência no dia a dia e se distanciem um pouco do método tradicional, baseado apenas em livros, mas ter criatividade para mostrar a ciência de outra maneira.

É importante superar o modelo tradicional de ensino, valorizando o conhecimento prévio dos alunos, a contextualização do ensino e ir além, como destaca Carvalho (2009, p.73), quando relata que devemos ensinar além de conceitos, leis e teorias já estruturadas, oportunizando os educandos elaborarem conhecimentos significativos e vivenciar o "fazer ciências" e "falar ciências".

Ainda, com relação a quais características seriam essenciais para ser um bom profissional na área, dois responderam que é necessário ter o conhecimento científico, ter uma boa formação e os outros três disseram que dedicação seria o aspecto central. Assim um dos entrevistados afirma que:

\footnotetext{
“A questão do conhecimento científico, eu acho, porque cada vez as coisas estão mudando e os conhecimentos científicos vão aprimorando cada vez mais então o professor tem que estar atento ao que está acontecendo, né?!” (A1).
}

Outro acadêmico sustenta que: 
"Dedicação, muito estudo, gostar do que faz, tá realmente dedicado a isso, inteiramente a isso, gostar do que tá fazendo e fazer por prazer não por obrigação ou pra ganhar dinheiro. Acho que é isso, muito estudo, muita dedicação, muito empenho" (A5).

Questionei se os acadêmicos sentiram algum tipo de preconceito por parte de familiares ou colegas de trabalho quando optaram pelo curso e no decorrer da formação, e se houve, como enfrentaram a situação. Apenas dois estudantes informaram que não sentiram nenhum tipo de preconceito, mas outros quatro alunos relataram que sim. Um dos alunos me chamou a atenção, em especial, por demonstrar muita indignação pelo fato de muitas pessoas não saberem que existe o curso na cidade e por ter sido questionado por outros professores sobre a certeza de seguir a carreira pela qual optou. Observemos um trecho de sua fala:

“A cidade parece que não sabe que existe esse curso há 20 anos, aí, te pergunta se você faz aqui na cidade mesmo, ai falam: você faz na UEM? Você faz engenharia? Eu falo não. Aí, as pessoas falam: mas tem ciências aqui? Eu falo: é aqui. Aí, algumas pessoas falam que ciências é pra professor. Tem algumas pessoas que ficam animadas porque eu estou fazendo um curso pra ter uma profissão e fica animado por ser professor. Mas, tem outras pessoas que não ligam, como se desanimasse você. Principalmente os professores quando você vai fazer estágio eles falam, tem certeza que você vai fazer isso? Esses tipos de coisa que te desanima” (A6).

Na sequência questionei como ele lidava como esse tipo de situação e o estudante me respondeu entusiasmado:

\footnotetext{
"Eu ignoro. No começo eu ficava meio assim, hoje, eu dou o máximo de mim, ignoro, quero terminar e eu gostei do curso e eu quero terminar ele, né?!Agora, eu vou ver isso na prática mesmo, né?!Talvez, o modo que eu vou tratar a sala de aula, os alunos seja diferente, vai ser diferente” (A6).
}

A última questão propunha um exercício de reflexão sobre como se imaginam no campo profissional daqui a alguns anos, a partir da inserção no curso de Licenciatura Plena em Ciências, os acadêmicos responderam que querem estar trabalhando, sendo que, cinco dos entrevistados disseram que pretendem ser professores, e um relatou que pretende sair da cidade para ter uma melhor oportunidade na carreira profissional. Vejamos nesta fala:

"Difícil, hoje mesmo a gente tava discutindo, na sala no primeiro horário, a gente busca daqui uns anos tá principalmente fora daqui da cidade né, porque a área de serviço aqui ta meio complicada, então, a gente fez inscrição para o concurso, fiz pra Toledo, que é uma cidade maior. Se eu passar, eu quero ficar lá, gosto muito de lá e continuar estudando, quero muito continuar estudando. Se passar em mestrado, farei mestrado, tentarei doutorado, fazer o máximo que eu puder e, ao mesmo tempo, trabalhando mesmo, buscando cada vez mais, né?!Cada vez ficar melhor na minha profissão. Então, eu quero é isso, partir para uma cidade maior, ta trabalhando na área mesmo, dando aula e continuar estudando nos próximos anos" (A5).

Diante das entrevistas e análise das mesmas, os acadêmicos do curso de Licenciatura Plena em Ciências apresentaram uma representação social pautada na formação conteudista, a qual entende que para serem professores bastariam o conhecimento científico, ou seja, evidenciaram que para ensinar, saber o conteúdo da disciplina para lecionar seria o suficiente.

Franco (2008) acredita que esta situação ocorre, pois as concepções de prática (como fazer), é o que nos faz aceitar o desconforto dos formandos em docência. Estes primeiros confrontos com os planejamentos e atividades da prática docente serão sempre situações que lhe trarão angústias, pois o modo como aprenderam em seu processo formativo, como estudantes, não os permite praticar segundo o que construíram como referencial a uma prática docente melhor. Desta maneira, aceitamos que a realidade será permeada de dissonâncias, ou seja, por representações onde caso tentarmos mudar, lhe causaria angústias e medo de fracassar. 
Para que possamos obter um resultado mais consistente, optamos como teste a evocação livre de palavras e conseguinte a redação sobre o mesmo tema "Ser Professor de Ciências", conforme descrito na metodologia. Após feitas as análises das evocações livre de palavras sobre "Ser professor de Ciências", as palavras que foram evocadas apenas uma vez durante a pesquisa, tendo como resultado frequência um (1), foram descartas dos estudos. Nas $3^{\text {as }}$ séries, em 2012 e 2013, analisamos 15 palavras evocadas repetitivamente e que, então, diante delas, formamos grupos semânticos de palavras que, posteriormente, originaram seis grupos. A média da frequência foi de três e a média das ordens médias de evocação (OME) foi de 2,45. A seguir, observaremos os valores que resultaram no Quadro I, onde nos apresenta os possíveis grupos que compõem as RS.

Quadro I - Elementos das RS referentes a Ser Professor de Ciências dos acadêmicos dos $3^{\circ}$ anos de 2012 e 2013 do Curso de Licenciatura Plena em Ciências

\begin{tabular}{|c|c|c|c|c|c|}
\hline \multicolumn{2}{|c|}{ Elementos Centrais - 10 quadrante } & \multicolumn{3}{c|}{ Elementos Intermediários - 2o quadrante } \\
\hline \begin{tabular}{|} 
Alta f e baixa Ordem Média de Evocações \\
$\mathrm{f} \geq 3$ e OME $<2,54$
\end{tabular} & \multicolumn{3}{c|}{$\begin{array}{c}\text { Alta F e alta Ordem Média de Evocações } \\
\mathrm{f} \geq 3 \text { e OME }>2,54\end{array}$} \\
\hline Grupo semântico de palavras & Freq. & OME & Grupo semântico de palavras & Freq. & OME \\
\hline Inteligente & 3 & 1,33 & Competente & 3 & 2,66 \\
& & & Ser dinâmico & 3 & 3 \\
\hline
\end{tabular}

Fontes: ?.

Por meio das evocações livres de palavras, análise qualitativa, aplicada nos $3^{\circ}$ anos de 2012 e 2013, tivemos como resultado do núcleo central, encontrada no primeiro quadrante do Quadro 1, a palavra "Inteligente", a qual obteve o índice de maior frequência com o maior grau de importância.

Ao analisarmos as redações, podemos destacar justificativas que explicam a escolha do núcleo central do quadro acima.

O aluno 7 afirma que: "O professor de ciências abrange várias disciplinas, isso o torna um tanto quanto sábio por saber um pouco de cada conteúdo”.

O aluno 1 sustenta que: "É ser inteligente saber o conteúdo que irá passar aos seus alunos, procurar mais informações para enriquecer seu conhecimento para assim passar aos seus alunos”.

O aluno 5 acredita que: "Para ser um bom professor de Ciências, o próprio nome já diz que é relacionado com a ciência, ou seja, pode haver mudanças, transformações, e a ciência evolui a cada dia mais”.

Nas redações analisadas, identificamos que as alunas acreditam que o professor de ciências é "inteligente”, pois a disciplina de Ciências reúne diversas áreas do saber acadêmico em apenas uma única disciplina e, também, que para ser um bom professor de ciências basta se aprofundar nos estudos que estarão aptos às aulas. Magalhães Júnior e Pietrocola (2011) apresentam a disciplina de Ciência como tendo o intuito de envolver os vários conteúdos, integrando diversas áreas das ciências naturais, como as áreas de Química, Física, Biologia e Geociências, assim, como ao realizarmos a pesquisa, as alunas identificaram como o núcleo central, que ser 
professor de ciências, é ser inteligente, possivelmente pelo fato de que esta disciplina reúne diversas áreas em uma só disciplina.

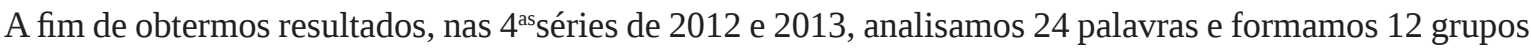
semânticos de palavras. A média da frequência foi de 3,5 e a média das ordens médias de evocação (OME) foi de 2,91. No quadro a seguir, observaremos os valores que resultaram no Quadro II, onde nos apresenta os possíveis grupos que compõem as RS dos $4^{\circ}$ anos.

Quadro II - Elementos das RS referentes a Ser Professor de Ciências dos acadêmicos dos $4^{\circ}$ anos de 2012 e 2013 do Curso de Licenciatura Plena em Ciências

\begin{tabular}{|c|c|c|c|c|c|}
\hline \multicolumn{3}{|c|}{ Elementos Centrais - 10 quadrante } & \multicolumn{3}{|c|}{ Elementos Intermediários - 20 quadrante } \\
\hline \multirow{2}{*}{\multicolumn{3}{|c|}{$\begin{array}{l}\text { Alta f e baixa Ordem Média de Evocações } \\
\qquad \text { f }>3,5 \text { e } \mathrm{OME}<2,91\end{array}$}} & \multirow{2}{*}{\multicolumn{3}{|c|}{$\begin{array}{l}\text { Alta F e alta Ordem Média de Evocações } \\
\qquad \mathrm{f}>3,5 \text { e OME }>2,91\end{array}$}} \\
\hline & & & & & \\
\hline Grupo semântico de palavras & Freq. & OME & Grupo semântico de palavras & Freq. & OME \\
\hline Conhecimento & 9 & 1,66 & Postura Profissional & 6 & 3,5 \\
\hline Sentimento & 4 & 2,5 & Meio ambiente & 5 & 4 \\
\hline \multicolumn{3}{|c|}{ Elementos Intermediários - 3o quadrante } & \multicolumn{3}{|c|}{ Elementos Periféricos - 40 quadrante } \\
\hline \multirow{2}{*}{\multicolumn{3}{|c|}{$\begin{array}{l}\text { Baixa F e baixa Ordem Média de Evocações } \\
\mathrm{f}<3,5 \text { e } \mathrm{OME}<2,91\end{array}$}} & \multirow{2}{*}{\multicolumn{3}{|c|}{$\begin{array}{l}\text { Baixa F e alta Ordem Média de Evocações } \\
\qquad \mathrm{f}<3,5 \text { e OME }>2,91\end{array}$}} \\
\hline & & & & & \\
\hline Grupo semântico de palavras & Freq. & OME & Grupo semântico de palavras & Freq. & OME \\
\hline Aprendizagem & 2 & 2 & Paciência & 2 & 4,5 \\
\hline Animais & 3 & 3 & Experimentos & 2 & 4,5 \\
\hline Vida & 2 & 1 & & & \\
\hline Criatividade & 2 & 2,5 & & & \\
\hline Ensino & 3 & 2,33 & & & \\
\hline Pesquisar & 2 & 3,5 & & & \\
\hline
\end{tabular}

Fontes: ?

A análise realizada indica que, possivelmente, o núcleo central das RS dos acadêmicos do quarto ano é formado por duas palavras apresentadas no primeiro quadrante, que foram "Conhecimento" e "Sentimento", as quais obtiveram o maior índice de frequência com o maior grau de importância.

De acordo com os resultados apresentados nas evocações de palavras, Franco (2008) acredita que para mudarmos a prática de ensino, o docente deve colocar-se no lugar do aluno: "Nesse olhar profundo e cotidiano de educadora-pesquisadora, percebi na prática algumas possibilidades de transformar o fazer docente, começando por oferecer ao professor as condições de se fazer como sujeito da história e protagonista de seu tempo e de seu trabalho" (FRANCO, 2008 p. 112). Deste modo, facilitaria como devemos pensar em formar o futuro professor para a prática docente, formação esta direcionada para a consolidação do ensino-aprendizagem.

Acerca disso, Franco (2008) acredita que os saberes pedagógicos serão possíveis com um sujeito que assume uma nova posição frente ao compromisso de ser professor, engajando-se criticamente em suas circunstâncias, atuando em sua realidade existencial, transformando-a em direção às suas intencionalidades. Deste modo o docente fará o uso do conhecimento didático, metodológico, cultural, servindo-se desse aparato teórico-prático, para ir construindo em ação as suas práticas pedagógicas.

Com as análises feitas das redações, destacamos parágrafos que nos auxiliaram e justificaram as escolhas do núcleo central do quadro acima. 
Sobre a palavra sentimento, o acadêmico 10 acredita que: "se o professor de ciências ensinar com amor e dedicação, com ética e consciente desse compromisso, ele terá maior probabilidade de alcançar o sucesso no ensino. [...] Ensinar ciências é antes de tudo, ter respeito e amor por sua profissão, só assim é que conseguimos repassar não apenas conteúdos, e sim valores”.

E o acadêmico 9 sustenta que: "Ser professor de Ciências significa ser pai, ser amigo, ser companheiro do aluno, é estar presente no dia a dia. Fazendo parte do seu crescimento e também aprendendo a cada dia, com os problemas e as dificuldades dos mesmos”.

Em relação ao Conhecimento, acadêmico 8 destaca que: "para ser um bom professor precisa-se ter um ótimo conhecimento, ou seja, para ensinar os alunos é preciso que este professor esteja por dentro do assunto a ser discutido com os estudantes".

O acadêmico 12 acredita que: “o ser professor de ciências é transmitir todo o tipo de conhecimento, relacionado aos conteúdos propostos de forma simples, fazendo com que os alunos se apropriem deste conhecimento para que possa ser útil em todo o decorrer da vida”.

O aluno 11 sustenta que se deve ter um conhecimento interdisciplinar: "Para ser um professor de ciências, é necessário ter muito conhecimento e domínio, pois é uma área muito ampla, abrangendo a matemática, física, química, biologia e áreas das humanas”.

As redações apontaram que para ser professor de Ciências, bastam terem amor e carinho pela profissão e, ainda, que se deve conhecer o que se ensina aos alunos. Magalhães Júnior e Tomanik (2013) sustentam que pós-graduandos na área das Ciências da Natureza, também consideram que saber o conteúdo a ser ensinado é suficiente para ensinar e ser professor desta área.

Competência, como saber ensinar, não foi algo que apareceu no núcleo desta representação, indicando uma visão acadêmica e racionalista desse grupo de licenciandos, onde o conhecer o conteúdo é tido como mais relevante no desenvolvimento da profissão de professor de ciências.

Acerca de uma melhor compreensão da influência das RS nas atividades de docência dos acadêmicos, analisamos os planejamentos das aulas para o estágio curricular supervisionado II do ano de 2013 e os relatórios sobre o estágio docência. Nos planejamentos e relatórios dos mesmos, foi possível perceber a dificuldade dos alunos em deixar o modelo tradicional de ensino, pautado no livro didático. Diante disto, estes graduandos apenas transmitiam o conteúdo aos alunos, não buscavam outros métodos e didáticas.

Para Rosa e seus colaboradores (2012) o estágio deve ser um elemento facilitador entre a teoria e prática, por sua vez o planejamento é essencial para que a didática seja conveniente à prática social, uma vez que o período em sala de aula é limitado, não sendo suficiente para elaboração das atividades sem antes planejar.

Para mesclar com o livro didático, todas as estagiárias usaram como recurso didático o datashow e os slides, mas, por sua vez, a teoria era trazida dos livros e não houve nenhuma aula que não tivesse este padrão.

Os graduandos vivem experiências durante o estágio, conhecem melhor a área que atuarão e tem a oportunidade de colocar em prática o conhecimento construído. Este é o processo indispensável na formação do estagiário, sendo a melhor maneira de fazer a transformação de graduando para professor (ROSA et al., 2012).

Deste modo, podemos acreditar os licenciandos do curso de Licenciatura Plena em Ciências da Universidade Estadual de Maringá, Campus Goioerê, não conseguem superar as representações sociais obtidas em 
sua trajetória escolar. Sendo assim, por meio dos métodos apresentados, consideramos que as alunas seguem o modelo tradicional de ensino pautado no livro didático.

\section{CONSIDERAÇÕES FINAIS}

Em meio aos problemas da prática educacional para atuação nos estágios e as dificuldades de alcançar um método satisfatório e didático pedagógico, foram necessários estudos acerca da formação de professores de ciências no Ensino Superior. Para tanto compreendemos as Representações Sociais e o Núcleo Central que influenciaram a prática pedagógica destes docentes em formação. Entendemos que investigá-los possibilita-nos compreender novas práticas educacionais e indicar novos caminhos à formação docente dos alunos que cursam a disciplina de Estágio Supervisionado I e II.

Como resultado, por meio das entrevistas semiestruturadas, os acadêmicos apresentaram uma representação social na formação de professores de Ciências pautada na formação conteudista, a qual entende que para ser professor bastaria o conhecimento científico, evidenciando que para ensinar bastaria saber o conteúdo da disciplina para lecionar.

Por meio da evocação livre de palavras e análise da redação acerca do tema "Ser professor de Ciências" obtivemos como resultado do núcleo central no $3^{\circ}$ ano "inteligente" e no $4^{\circ}$ ano as palavras "conhecimento e sentimento".

Por fim realizamos a análise dos planos de aulas e relatórios da disciplina de estágio curricular supervisionado II do ano de 2013, diante disto foi possível acentuar que a representação social que possuem sobre "ser professor de ciências", são baseadas no livro didático, e a aula pautada na teoria tradicional de ensino, onde o aluno é apenas o receptor de aprendizagem, e o professor o transmissor.

Assim, acreditamos que os licenciandos do curso de Licenciatura Plena em Ciências da Universidade Estadual de Maringá, Campus Goioerê, não conseguem superar as representações sociais obtidas em sua trajetória escolar. 


\section{REFERÊNCIAS}

ABRIC, Jean-Claude. A abordagem estrutural das representações sociais. In.: MOREIRA, Antonia Silva Paredes; OLIVEIRA, Denize Cristina (Org.). Estudos Interdisciplinares de Representação Social. 2 ed. Goiânia: AB, 2000. p. 27-38.

ALVES-MAZZOTTI, Alda Judith. Representações sociais: desenvolvimentos atuais e aplicações à educação. In: CANDAU, Vera Maria. Linguagens, espaços e tempos no ensinar e aprender, $2^{\mathrm{a}}$ Ed. Rio de Janeiro: DP\&A, 2001. p. 57-73.

BARDIN, Laurence. Análise de conteúdo. Lisboa: Edições 70; 1977.

CAMPOS, Pedro Humberto Faria, ROUQUETTE, Michel-Louis. Abordagem estrutural e componente afetivo das representações sociais. Psicologia: Reflexão e Crítica, 2003, 16(3), 435-445.

CARMO, Tânia do; LEITE, Joici de Carvalho; MAGALHÃES JÚNIOR, Carlos Alberto de Oliveira. Aspectos Metodológicos em Representações sociais: um olhar para as pesquisas no contexto educacional. In.: TRIANI, Felipe da Silva; MAGALHÃES JÚNIOR, Carlos Alberto de Oliveira; NOVIKOFF, Cristina. Representações Sociais e Educação: contextos e perspectivas. Rio de Janeiro: Autografia, 2017.

CARVALHO, Anna Maria Pessoa; GIL-PEREZ, Daniel. Formação de professores de Ciências: tendências e inovações. 8 ed. São Paulo: Cortez, 2006.

CORTES JUNIOR, Lailton Passos; CORIO, Paola; FERNANDEZ, Carmen. As Representações sociais de química ambiental dos alunos iniciantes na graduação em química. Química Nova na Escola, São Paulo, n. 1, v. 31, p. 46-54, fev. 2009.

DOISE, Willem. Atitudes e representações sociais. In: JODELET, Denise. As representações sociais, Rio de Janeiro: Uerj, 2001. p. 187-200.

FRANCO, Maria Amélia Santoro. Entre a lógica da formação e a lógica das práticas: a mediação dos saberes pedagógicos. Educação e Pesquisa, São Paulo, v.34, n.1, p. 109-126, jan./abr. 2008.

GATTI, Bernadete Angelina. Formação continuada de professores: a questão psicossocial. Cadernos de Pesquisa, n. 119, p. 191-204, julho, 2003.

GILLY, Michel. As representações sociais no campo da educação. In: JODELET, Denise, As representações sociais, Rio de Janeiro: Uerj, 2001. p. 321- 337.

HUBERMAN, Michlael. O ciclo de vida profissional dos professores. In: NÓVOA, António. (org.). Vida de professores. Porto: Porto Editora, 1995. p.31-61.

JODELET, Denise. Loucuras e representações sociais. Petrópolis: Vozes, 2005.

Representações sociais: um domínio em expansão. In: As representações sociais, Rio de Janeiro: Uerj, 2001. p. 17- 41.

KAES, René. Psicanálise e representação social. In: JODELET, D. As representações sociais. Rio de Janeiro: Uerj, 2001. p. 67-87.

MAGALHÃES JÚNIOR, Carlos Alberto de Oliveira; PIETROCOLA, Maurício. Atuação de professores formados em licenciatura plena em ciências. Alexandria (UFSC), v. 4, p. 175-198, 2011 
MAGALHÃES JÚNIOR, Carlos Alberto de Oliveira; TOMANIK, Eduardo Augusto. Representações sociais e direcionamento para a educação ambiental na reserva biológica das perobas, Paraná. Investigações em Ensino de Ciências. Porto Alegre, n.1, v.17, p. 227-248. Maio, 2012.

MAGALHÃES JÚNIOR, Carlos Alberto de Oliveira; TOMANIK, Eduardo Augusto. Representações sociais de meio ambiente: subsídios para a formação continuada de professores. Ciência \& Educação, n.1, v. 19, p. 181-199. 2013.

MARQUES, Sergio Corrêa; OLIVEIRA, Denize Cristina de; GOMES, Antonio Marcos Tosoli. AIDS e Representações Sociais: uma análise comparativa entre subgrupos de trabalhadores. Psicologia: Teoria e Prática, São Paulo, ed. especial, p. 91-104, 2004.

MOSCOVICI, Serge. Introcuction à La psychologie sociale. Paris: Larousse, 1972.

A representação social da Psicanálise. Rio de janeiro: Zahar Editores, 1978.

NAIFF, Denis Giovani Monteiro; NAIFF, Luciene Alves Miguez; SOUZA, Marcos Aguiar de. As representações sociais de estudantes universitários a respeito das cotas para negros e pardos nas universidades públicas brasileiras. Estud. pesqui. psicol., n.1, v. 9, p. 216-229, 2009.

ROCHA, Adauto Galvão da. Representações Sociais sobre novas tecnologias da informação e da Comunicação: novos alunos, outros olhares. 2009. 314f. Dissertação de Mestrado apresentada à Pós-graduação em Educação da Universidade Católica de Santos, Santos, 2009.

ROSA, Jeâni Kelle Landre; WEIGERT, Célia; SOUZA, Ana Cristina Gonçalves de Abreu. Formação docente: reflexões sobre o estágio curricular. Ciência \& educação, v. 18, n. 3, p. 675-688, 2012.

SÁ, Celso Pereira. Núcleo das representações sociais. Petrópolis: Vozes, 1996.

A representação social da economia brasileira antes e depois do plano real. In.: MOREIRA, Antonia Silva Paredes; OLIVEIRA, Denize Cristina (Org.). Estudos Interdisciplinares de Representação Social. 2 ed. Goiânia: AB, 2000. p. 49-69.

SAVIANI, Dermeval. Formação de professores: aspectos históricos e teóricos do problema no contexto brasileiro. Revista Brasileira de Educação, v. 14 n. 40 jan./abr. 2009.

TRIANI; Felipe da Silva; et al., O corpo e suas representações sociais no discurso científico. EFDeportes. com, Revista Digital. Buenos Aires, Año 20, Nº 209, Octubre de 2015. 